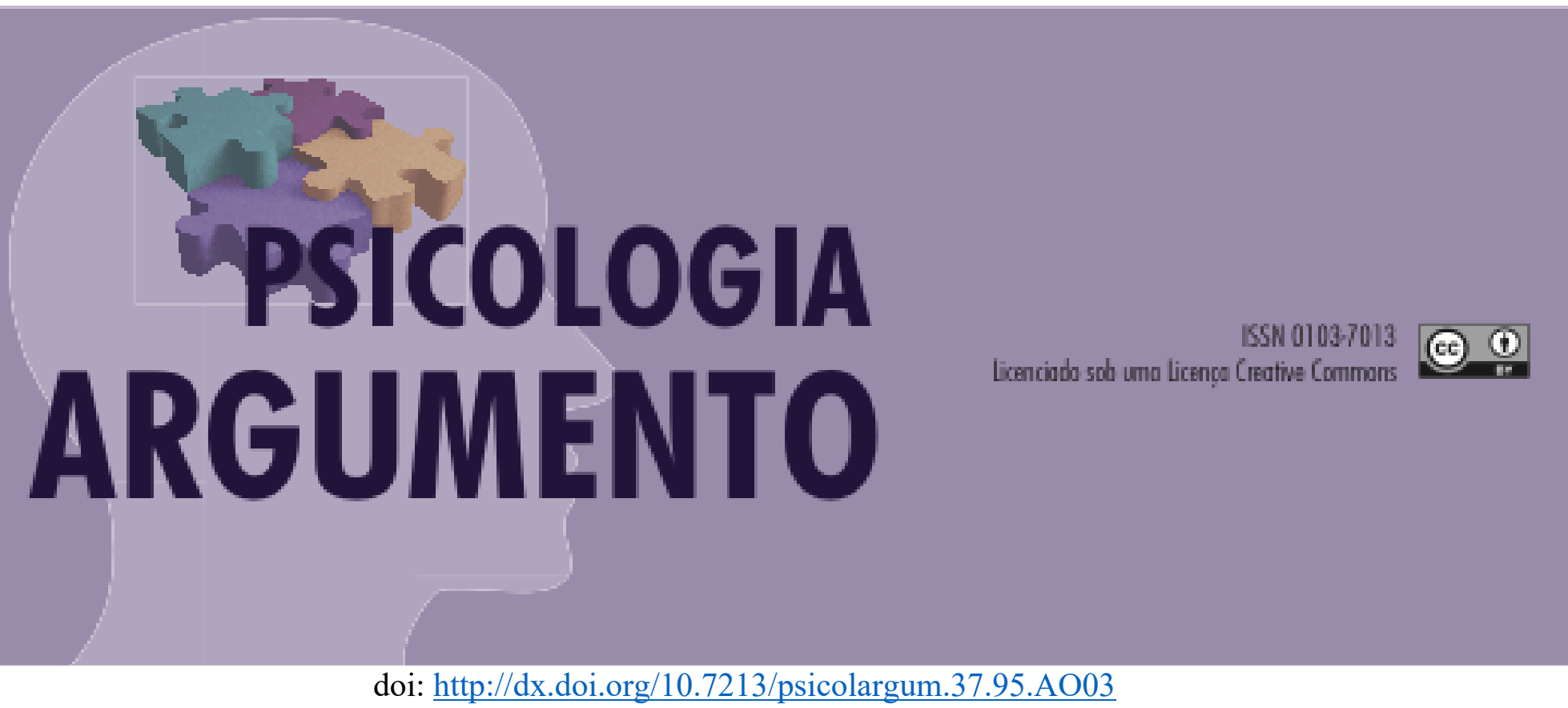

doi: http://dx.doi.org/10.7213/psicolargum.37.95.AO03

\title{
Projeto Mulheres da Paz: percursos históricos e interseccionalidades
}

\author{
Women of Peace Project: historical paths and intersectionalities
}

Proyecto Mujeres de Paz: caminos históricos e interseccionalidades

\section{Michele Nunes D Ávila \\ https://orcid.org/0000-0003-1471-3303}

Mestrado em Psicologia Social e Institucional - Universidade Federal do Rio Grande do Sul (UFRGS) Canoas, Rio Grande do Sul, Brasil.Email: michelendavila@gmail.com

Henrique Caetano Nardi

\author{
https://orcid.org/0000-0001-6058-1642
}

Docente da Universidade Federal do Rio Grande do Sul (UFRGS), Programa de Pós-Graduação em Psicologia Social e Institucional.Porto Alegre, Rio Grande do Sul,

Brasil. Email: hcnardi@gmail.com

Raquel da Silva Silveira

https://orcid.org/0000-0002-8002-8059

Docente da Universidade Federal do Rio Grande do Sul (UFRGS), Programa de Pós-Graduação em Psicologia Social e Institucional. Porto Alegre, Rio Grande do Sul,

Brasil.Email: raquelsilveira43@gmail.com

\section{Resumo}

Este artigo propõe-se ao mapeamento histórico do Projeto Social Mulheres da Paz no município de Canoas/RS. Foram apontados os percursos desde sua criação até suas reformulações no ano de 2016. O fio condutor desta discussão foi a interseccionalidade dos marcadores sociais, além 
de elementos correspondentes à relação desse projeto social com os processos de subjetivação das participantes. O Projeto Mulheres da Paz carrega em sua história elementos que correspondem às disputas vivenciadas entre os diferentes movimentos de mulheres e movimentos feministas, que apontam para a discussão da interseccionalidade dos marcadores sociais que atravessam essas disputas e posições. Outro fator com destaque neste estudo, diz respeito ao enfraquecimento das políticas públicas para as mulheres, já que ações que implicam em transformações nas relações de sociais de gênero, como o exemplo do Projeto Mulheres da Paz, estão perdendo a visibilidade e encerrando suas atividades.

Palavras-chave: Mulheres da Paz; Interseccionalidades; Políticas Públicas; Gênero.

\section{Abstract}

This article proposes a historical mapping of the Women of Peace Social Project in the municipality of Canoas/RS. The paths since its creation until its last reformulations in 2016. The guiding thread of this discussion was the intersectionality of social markers, as well as elements corresponding to the relationship of this social project with the subjectivation processes of the participants. The Women of Peace Project carries in its history elements that correspond to conflicts between different perspectives of women movements and feminist movements, which points to the discussion of the intersectionality of the social markers that cross these disputes and positions. Another factor that stands out in this study is the weakening of public policies for women, since actions that imply transformations in social relations of gender, like the Women of Peace Project, are losing the visibility and closing their activities.

Keywords: Women of Peace; Intersectionalities; Public policies; Gender.

\section{Resumen}

Este artículo propone el mapeo histórico del Proyecto Social de Mujeres de Paz en la ciudad de Canoas / RS. Se señalaron los caminos desde su creación hasta sus reformulaciones en 2016. El hilo conductor de esta discusión fue la interseccionalidad de los marcadores sociales, así como los elementos correspondientes a la relación de este proyecto social con los procesos de subjetivación de los participantes. El Proyecto Mujeres de Paz lleva en su historia elementos que corresponden a las disputas experimentadas entre los diferentes movimientos de mujeres y movimientos feministas, que apuntan a la discusión sobre la interseccionalidad de los marcadores sociales que cruzan estas disputas y posiciones. Otro factor importante en este estudio es el debilitamiento de las políticas públicas para las mujeres, ya que las acciones que implican transformaciones en las relaciones sociales de género, como el Proyecto Mujeres de Paz, están perdiendo visibilidad y terminando sus actividades.

Palabras clave: Mujeres de paz; Interseccionalidades; Políticas públicas; Género

\section{Introdução}

Este artigo é resultado de uma pesquisa mais ampla que discute de que forma a interseccionalidade dos marcadores sociais de gênero, raça, classe e geração/idade atravessam a relação das mulheres com o Projeto Mulheres da Paz. O foco na análise aqui apresentada é o mapeamento histórico deste projeto social no município de Canoas/RS. O fio condutor desta discussão foi a interseccionalidade dos marcadores sociais apontados, além de elementos correspondentes à relação desse projeto social com os processos de subjetivação das participantes. 
Esta pesquisa utilizou como método o relato das histórias de vida de 10 mulheres da paz que foram entrevistadas individualmente, além do aporte teórico pautado nos marcadores conceituais de interseccionalidade de Kimberlé Crenschaw e a compreensão dos processos de subjetivação a partir de Michel Foucault.

De acordo com as proposições de Michel Foucault (1994) a compreensão do sujeito, a partir da produção de subjetividade, é entendida a partir das relações de saberpoder que atravessam as relações sociais. A ideia do sujeito como uma unidade psicológica "autônoma" é problematizada a partir da compreensão de que ele se produz a partir da experiência de si que é construída na relação com um determinado jogo de verdades. Assim trata-se de um sujeito inscrito numa trama histórica que lhe oferece condições para a construção de si no registro do social. Nesse sentido, a vida é efeito de um campo de possibilidades em que estão em jogo regimes de verdade que potencializam determinados processos de subjetivação em detrimento de outros, sendo estes a forma particular como cada um(a) estabelece (ou pode estabelecer) uma relação específica com estas regras em arranjos singulares que caracterizam as trajetórias de vida. (Nardi, 2006)

Quanto ao Projeto Social Mulheres da Paz, neste artigo, se percorrerá pelas etapas de sua criação enquanto ação do Programa Nacional de Segurança Pública com Cidadania (PRONASCI), fazendo destaque às disputas entre os diferentes movimentos de mulheres que construíram o programa. Em seguida, será contextualizado este projeto social em Canoas, descrevendo sua execução e os desafios encontrados diante da multiplicidade dos marcadores sociais de suas participantes. Por fim, será apontado o marco de reformulação do Projeto Mulheres da Paz neste município, salientando sua relação nos processos de subjetivação das participantes, a fim de questionar o enfraquecimento que as políticas públicas sociais de gênero vivenciam na atualidade.

\section{O PRONASCI e as mulheres da paz}

O Programa Nacional de Segurança Pública com Cidadania (PRONASCI), instituído pela Lei $\mathrm{n}^{\circ} 11.530$ em 2007, foi um programa do Ministério da Justiça que se destinou a articular ações de segurança pública para a prevenção, controle e repressão da criminalidade, estabelecendo políticas sociais e ações de proteção às vítimas. Propondo-se a articular políticas de segurança por meio de ações sociais, priorizando a prevenção e as ações diretas nas causas que levam à violência. 
As ações pensadas e consolidadas pelo PRONASCI foram divididas em dois eixos: as "ações estruturais" e os "projetos locais". O Projeto Mulheres da Paz esteve vinculado aos "projetos locais", aos quais estiveram vinculados à criação dos chamados Territórios de Paz nos bairros com alto índice de violência.

O Projeto Mulheres da Paz consistiu na ação de número 61 do conjunto de noventa e quatro ações do PRONASCI, compondo o eixo Integração do Jovem e da Família. Este projeto social teve como proposta capacitar grupos de mulheres com perfil de liderança para construir redes comunitárias e sociais para a prevenção e enfrentamento às violências nas regiões atendidas pelo programa. Sua principal e inicial finalidade foi promover a aproximação das mulheres que o integrassem com os/as jovens de suas comunidades para encaminhá-los/as aos projetos sociais, prioritariamente ao PROTEJO (projeto social do PRONASCI destinado aos/às jovens), e acompanhá-los/as em seu percurso social e formativo.

Essas formações foram realizadas no período de doze meses, nos anos de 2010 a 2015 e previam mensalmente uma bolsa de $\mathrm{R} \$ 190,00$ para cada participante frequentar os encontros. Foram atividades estruturadas de acordo com seguinte tripé de atuação: prevenção da violência doméstica e de gênero, mobilização comunitária e articulação com a rede local de atendimento e prevenção da violência juvenil. E foi com base nesse tripé que os conteúdos discutidos na formação foram elencados e propostos pelo Ministério da Justiça (2012).

Por meio de oficinas, os temas foram trabalhados pelas equipes locais, que planejavam e executavam estes momentos, construindo o cronograma de atividades. Foram também convidadas(os) profissionais que contribuíssem para as discussões bem como integrassem à rede de serviços das localidades do programa. A maioria dos encontros aconteceu na sede local do Projeto Mulheres da Paz que varia de município para município.

Os critérios de seleção das mulheres selecionadas previam que elas fossem moradoras do(s) bairro(s) correspondente(s) ao Território de Paz, fossem alfabetizadas e possuíssem idade mínima de 16 anos. A formação teve uma carga horária de formação teórica inicial de 48 horas e a etapa seguinte que incluiu formações também práticas que corresponderam a 176 horas (média de 16 horas por mês).

Mulheres da paz: o ponto de partida 
Instituído pela Lei $n^{\circ} 11.530 / 2007$, o Projeto Mulheres da Paz foi nomeado no primeiro momento como "Mães da Paz", com este nome, o projeto foi uma proposta inicial de autoria da Central Única das Favelas (CUFA) que, devido às ações que realizava nas periferias brasileiras junto com diversas associações nelas criadas, ressaltou a relevância do ativismo das mulheres nas comunidades, na mobilização em prol da justiça e da paz. A ideia se construiu com base na importância, atribuída pela CUFA, ao vínculo moral e afetivo que era estabelecido entre as mulheres e os jovens de suas comunidades, possibilitando, portanto, uma abordagem preventiva ao envolvimento criminal desses jovens, por meio do aconselhamento e orientação (Pinheiro, 2013).

O percurso metodológico de formulação do projeto até então nomeado Mães da Paz se deu por meio de reuniões que foram promovidas em diferentes comunidades brasileiras, com as mulheres que lá residiam e que foram contatadas pela CUFA, seguidas de encontros sistematizados dos quais participaram movimentos da sociedade civil organizada. A partir destes encontros foram organizados grupos de trabalho, com o objetivo de delinear a proposta de criação do projeto.

Algumas tensões se destacaram neste processo de construção do projeto até então chamado "Mães da Paz". Tensões que foram explicitadas pelos conflitos e divergências entre alguns movimentos feministas e os outros movimentos de mulheres que, orientadas por referenciais e objetivos distintos, defenderam posicionamentos igualmente díspares acerca de muitos temas, dentre os quais se salientou o nome do projeto (Pinheiro, 2013).

A partir do estudo de Ana Pinheiro (2013) se afirmou que as críticas direcionadas a este aspecto (o nome do projeto) foram contundentes, especialmente, por parte do movimento feminista "Articulação de Mulheres Brasileiras" (AMB), que compreendeu que o nome limitava-se a uma concepção naturalizada e essencialista sobre a mulher, reforçando as construções tradicionais de gênero presentes na sociedade, por meio das quais se acredita que a maternidade faz parte da natureza da mulher, em que sua função social se resume ao cuidado da família e dos/as filhos/as. De maneira enfática, a AMB questionou a proposta, se posicionando contrariamente a ela, afirmando que "as feministas não podiam silenciar, mesmo diante de sua nomenclatura, conservadora e essencialista, situando a mulher-mãe como a cuidadora, responsável una por cuidar e educar" (Teixeira, 2009 p.22). 
Ao fim de todo o debate, conseguiu-se um consenso em torno do nome "Mulheres da Paz", considerando o fato de que suas principais beneficiárias eram mulheres e prevalecendo a noção de que a maioria dos movimentos em favor da paz é liderada por mulheres. As produções de todo esse processo deram origem a um relatório utilizado pela equipe responsável pela elaboração do projeto, com o objetivo de definir a concepção e a formulação final do Projeto Mulheres da Paz.

Neste contexto, Ana Pinheiro (2013 p. 56) destaca as tensões do próprio movimento entre "as mulheres que não se identificavam com o movimento feminista" e as feministas. Como destaca a autora, estes entraves não são tensões recentes e envolvem as transformações históricas do movimento feminista brasileiro, marcado por clivagens de origem racial, de classe, geográficas, etc, que se constituíram no movimento e que se manifestam nos espaços onde o que está em jogo é a visibilidade política. Nos grupos de discussão acerca da proposta do projeto, as mulheres não identificadas com o feminismo relataram que se sentiram "sufocadas" pelas feministas, e não gostariam de trabalhar com elas.

Para Ana Alice Alcântara Costa (2005), falas como esta, ressaltam os conflitos que emergiram naquele espaço, demonstrando a persistência das cisões existentes entre alguns movimentos de mulheres e o movimento feminista. Cisões surgidas pelo modo diverso como ambos compreendem o mundo e o lugar da mulher nesse mundo, se inserindo, por consequência, em lutas também diversas.

O nome do projeto foi apenas um dos pontos onde essas disputas apareceram de modo incisivo, mas que correspondia também aos marcadores sociais que atravessam as histórias das mulheres e os modos pelos quais as políticas públicas, neste caso o Projeto Mulheres da Paz, se construiu, e os caminhos particulares que este programa foi desbravando na prática em cada experiência.

Em 2008, o PRONASCI como um todo foi reformulado, recebendo, inclusive, nova redação que foi logo convertida na Lei Federal 11.707, em 19 de junho de 2008. Essa nova lei também reformulou as atribuições e definições do projeto "Mães da Paz", modificando o seu nome, passando a denominá-lo "Projeto Mulheres da Paz".

A Lei 11.707/08 manteve a definição de que o projeto Mulheres da Paz seria destinado à formação de mulheres socialmente atuantes nas áreas geográficas abrangidas pelo PRONASCI. Entretanto, redefiniu suas atribuições, dispondo que o trabalho a ser desenvolvido por elas passaria a ter como foco: a) a mobilização social 
para afirmação da cidadania, tendo em vista a emancipação das mulheres e prevenção e enfrentamento da violência contra as mulheres; b) e a articulação com jovens e adolescentes, com vistas à sua participação e inclusão em programas sociais de promoção da cidadania e na rede de organizações parceiras capazes de responder de modo consistente e permanente às suas demandas por apoio psicológico, jurídico e social. (Brasil, 2008 ). Acrescentando-lhes também as funções de: divulgar e implantar ações que orientem a comunidade na prevenção e redução da violência; visitar as famílias e conversar com parentes dos jovens para conhecer melhor a situação de cada um deles e; juntamente com a equipe multidisciplinar promover palestras, oficinas ou trocas de experiências que impulsionem práticas de direitos humanos, de proteção da vida e estimulem a cultura da paz. (Secretaria Especial de Políticas para as Mulheres, 2008)

Nessa nova versão, suas competências foram ampliadas, passando a dar maior visibilidade às questões referentes à cidadania e proteção das mulheres (que passaram a serem vistas como beneficiárias da política e não somente os/as jovens). Entretanto, depois da revisão, o entendimento do movimento feminista foi de que a mudança da redação não alterava a concepção do projeto, o que gerou certo descontentamento diante da desconsideração às suas principais críticas, já que também houve questionamento sobre em que medida a mudança na redação traria mudanças reais, no plano prático, para a situação e atuação das mulheres da paz. (Pinheiro, 2013)

Analba Teixeira (2009) destacou a crítica das feministas às principais diretrizes do projeto no que se referia às questões de gênero. Ela ressaltou que apesar de todas as construções críticas na elaboração do projeto Mulheres da Paz "o máximo que conseguiram, após séries de discussões e três reuniões no Ministério da Justiça, foi a modificação do nome do programa" (Teixeira, 2009 p23.)

Claudia Mayorga (2014), ao salientar as tensões existentes entre os feminismos, aponta como exemplo, um debate com uma ativista feminista lésbica em Madri, em uma discussão acerca das diferenças entre os feminismos dos contextos latino-americano e espanhol. A autora relata que uma ativista teria sido bastante categórica ao afirmar que o problema das latinas referia-se ao fato de elas ainda se casarem, terem filhos etc. Para a autora, é importante afirmar que a instituição do casamento e a designação da maternidade como lugar natural para as mulheres, foram aspectos criticados pelo feminismo, por sua forte relação e função nas lógicas patriarcais, mas que tal afirmação 
revela uma posição de prescrição de formas de emancipação que foi e segue sendo alvo de tensões dentro do feminismo. Neste sentido a preocupação se volta, sobretudo, para posições que subordinam outras mulheres, sem escutar suas vozes, entender suas experiências e distinguir os contextos onde vivem.

Os estudos das feministas negras norte-americanas, com destaque a Kimberlé Crenshaw (2002), enfatizam que foi a partir desse antagonismo dentro do próprio feminismo que nasceu a noção de interseccionalidade. $O$ conceito de interseccionalidade a partir de Kimberlé Crenshaw (2002) aponta que embora todas as mulheres estejam sujeitas à discriminação de algum modo, outros marcadores sociais como raça, classe, religião, orientação sexual, nacionalidade, estabelecem distinções que fazem a diferença na maneira como estes múltiplos grupos de mulheres vivenciam a discriminação. O gênero precisa ser pensado em suas imbricações com estes outros marcadores sociais para que possa ser entendido em uma dimensão descritiva e analítica.

Judith Butler (2003 p20), ao problematizar a categoria "mulher" como sujeito do feminismo, afirma que "se alguém é uma mulher, isso certamente não é tudo o que esse alguém é”. O gênero estabelece intersecções com marcadores raciais, de classe, étnicos, sexuais e regionais de identidades discursivamente constituídas, tornando-se impossível separar a noção de gênero das intersecções políticas e culturais em que invariavelmente ela é produzida e mantida. (Butler, 2003).

Estas autoras, bem como a história de criação do Projeto Mulheres da Paz, destacam divergências políticas no interior dos movimentos feministas que apontam para muitas imbricações que produzem subjetividades. Esses embates entre grupos de mulheres representam suas lutas, que por vezes se diferem, fazendo com que as políticas públicas, dando ênfase ao Projeto Mulheres da Paz, sejam desenvolvidas de determinada forma.

É pertinente trazer à tona os questionamentos acerca desse papel "maternalista" naturalizado de mulheres que vão assumir mais uma vez o lugar de tutela de "jovens". Contudo, devemos também cuidar para que não nos ceguemos diante de uma demanda cotidiana, em que mulheres mães estão organizadas a partir do desejo de preservar a vida dos/as filhos/as, por exemplo.

Das mulheres da paz que estavam vinculadas ao programa no quadrante nordeste em Canoas, até fevereiro de 2016, apenas duas afirmaram não ter filho/a(s). Muitas 
dessas mulheres também se interessam por ações diversas, como por exemplo: ações voltadas para idosos/as, para crianças nas escolas, nas Unidades Básicas de Saúde, nas associações de moradores, nos centros de economia solidária, em projetos de geração de renda. Espaços e demandas que correspondem aos acontecimentos cotidianos concebidos pelo campo de possibilidades que o tempo-espaço produz, isto é, os processos de subjetivação alçam condições de existência a partir de um determinado lugar/posição e período que nos encontramos, podendo variar, por exemplo, entre um grupo de mulheres que não possuem filhos/as e aquelas que compreendem sua razão de ser enquanto "mães".

Uma das temáticas que o Projeto Mulheres da Paz conseguiu consolidar entre os diferentes movimentos de mulheres, desde sua emergência até sua implantação em Canoas, por exemplo, foi a questão do enfrentamento à violência doméstica e familiar contra às mulheres. Este ponto elucida uma luta por agendas políticas, em que escutar o que os diferentes grupos de mulheres estão querendo dizer é uma aposta para reconhecermos o lugar de fala, de grito ou até mesmo de silêncio umas da(s) outra(s).

\section{O Projeto Mulheres da Paz em Canoas}

O Projeto Mulheres da Paz, vinculado à Secretaria Municipal de Segurança Pública e Cidadania (SMSPC) e ao Ministério da Justiça, iniciou suas atividades no município de Canoas em março de 2010 com formações voltadas para moradoras do bairro Guajuviras, que foi o primeiro foco territorial estabelecido pelo PRONASCI, para que fosse o pioneiro Território de Paz do município, em razão do alto índice de violência que caracteriza a região. Durante os três anos seguintes foram realizadas formações voltadas para as moradoras deste bairro, formando no final de 2012, 107 mulheres. Essas formações duraram 12 meses, com dois encontros por semana, prevendo uma bolsa mensal no valor de $\mathrm{R} \$ 190,00$ (verba federal) para cada participante.

Após esses 12 meses de formação, a Prefeitura Municipal de Canoas propôs um novo convênio com as mulheres que desejassem seguir vinculadas ao programa. Para tanto seria disponibilizada uma bolsa de ressarcimento no valor de $\mathrm{R} \$ 100,00$ por intermédio de uma verba municipal, pensada para cobrir as despesas de transporte das participantes. 
Essa etapa, após os 12 meses de formação, se constituiu em formação continuada, por meio de oficinas, bem como planejando e executando ações comunitárias. Os valores das bolsas foram diferentes em razão dos convênios estabelecidos, a bolsa federal recebida via Ministério da Justiça (PRONASCI) era maior que a bolsa da Prefeitura. Ressalta-se que do ano de 2013 ao final de 2015, ficaram vigorando duas bolsas com valores diferentes, ou seja, umas recebiam $\mathrm{R} \$ 190,00$ mensais e outras $\mathrm{R} \$ 100,00$ mensais no mesmo período, já que algumas turmas de formação já haviam concluído o período de 12 meses e outras ainda não.

Dentre as atuações, atividades e objetivos, o Projeto Mulheres da Paz em Canoas/RS carregou em sua história o fortalecimento do trabalho voltado para a discussão das relações de gênero. Esse percurso que se construiu a partir da demanda do grupo de mulheres que participaram desde o seu início, bem como da organização não governamental Themis - gênero, justiça e direitos humanos, que executou o projeto de 2009 a 2012 (a partir de 2012 a Fundação La Salle assumiu a execução do programa).

A partir de 2013 outras mudanças no Projeto Mulheres da Paz também aconteceram. O Ministério da Justiça, bem como a Prefeitura Municipal expandiram a formação proposta pelo Projeto Mulheres da Paz para quatro bairros do entorno do Guajuviras, visando dar conta dos cinco bairros que compõem o Quadrante Nordeste do município de Canoas.

Novas mulheres dos bairros Igara, São José, Estância Velha e Olaria também iniciaram a formação pelo convênio com o Ministério da Justiça, ao mesmo tempo em que as outras mulheres do Guajuviras seguiram conveniadas ao projeto pela Prefeitura. Em julho de 2015, 38 mulheres destes bairros do entorno do Guajuviras finalizaram a formação, totalizando 151 participantes que concluíram a formação desde 2010 no Quadrante Nordeste.

Através do Projeto Mulheres da Paz, as participantes planejavam e desenvolviam ações em suas comunidades, com um enfoque nas questões de gênero e juventudes. Esses trabalhos foram em grande parte realizados de forma coletiva. As atividades aconteceram tanto na sede do projeto, por meio de oficinas de formação e reuniões de planejamento e em espaços dos serviços da rede de políticas públicas.

Essas ações em espaços dos serviços da rede foram desenvolvidas nas escolas (em eventos para famílias, intervalos e salas de aula), nas Unidades Básicas de Saúde (sala de espera e reuniões com as/os agentes comunitários/as de saúde) do território, por 
intermédio de oficinas informativas, rodas de conversas e balcões de informação, nos CRAS e projetos sociais dos bairros. Todas as atividades tiveram como tema central assuntos relacionados às violências de gênero contra as mulheres, em que materiais explicativos eram distribuídos e realizavam-se rodas de conversas sobre os tipos de violência, Lei Maria da Penha, informações sobre a rede de serviços especializados e possibilidades de encaminhamento. Além disso, houve a participação em manifestações sociais (passeatas, marchas, encontros) e espaços de controle social como: seminários municipais, conferências, plenárias, orçamento participativo, conselho municipal de saúde, entre outras atividades.

Um marco diferencial do Projeto Mulheres da Paz em Canoas, é que este foi o único município do país que manteve essa iniciativa desde 2010, por incentivo da prefeitura juntamente com a gestão e direção municipal do projeto em propor a continuidade do pagamento de bolsas, bem como construir junto às mulheres um diálogo e planejamento de atividades mesmo após a formação de 12 meses, incentivando que as participantes seguissem vinculadas ao programa.

Até o início de 2016, em torno de 50 mulheres da paz frequentavam o Projeto semanalmente. Entretanto, o pagamento da bolsa de $\mathrm{R} \$ 100,00$ mensais foi suspenso no final do ano de 2015 em função das transformações ocorridas nos projeto sociais vinculados a Secretaria Municipal de Segurança Pública com Cidadania.

É preciso ressaltar que os cinco bairros que compõem o quadrante nordeste de Canoas (território de abrangência do programa), são bairros que possuem algumas diferenças que merecem destaque. O bairro Guajuviras, no ano de 1987, foi cenário de ocupação pelo movimento social de luta por moradia. Milhares de casas e apartamentos foram ocupados por pessoas e famílias de classes populares, dando início à história do bairro. Com base nos dados da Prefeitura de Canoas/Instituto Canoas XXI (2013) atualmente o bairro Guajuviras possui uma população média de 40.000 moradoras/es, com renda média mensal por pessoa entre $\mathrm{R} \$ 700,00$ e $\mathrm{R} \$ 770,00$.

Os bairros Estância Velha e Olaria são bairros mais antigos, predominantemente residenciais e com população respectiva de aproximadamente 25.000 e 10.000 moradoras/es com renda média mensal por pessoa de $\mathrm{R} \$ 800,00$ a $\mathrm{R} \$ 900,00$. Já os bairros Igara e São José são identificados como os bairros mais novos no município com cerca de 10.000 moradoras/es cada um e com rendimentos médios mensais de $\mathrm{R} \$ 1200,00$ a $\mathrm{R} \$ 1300,00$ por pessoa. Os dados referentes à raça/cor da da população 
total do município, dos aproximados 323.000 moradores/as, 84\% são brancos/as, 6\% pretos/as e 8\% pardos/as, dados semelhantes ao percentual de negros no Estado do Rio Grande do Sul.

As diferenças que permeiam esses bairros foram visibilizadas no cotidiano do trabalho no Projeto Mulheres da Paz, fazendo com que empiricamente sentíssemos as limitações de pensarmos e olharmos para essas "mulheres" como se fossem uma única categoria, como se estivéssemos falando de uma ideia universal de mulher. São mulheres brancas, pretas, pardas, mulheres jovens, adultas, idosas, mulheres que não possuem renda própria, mulheres que ganham mais de 10 salários mínimos, mulheres que perderam seus filhos violentamente ou que os visitam semanalmente na prisão, mulheres que não possuem filhos/as, ou ainda aquelas que são agredidas por estes/as. Mulheres evangélicas, católicas, umbandistas, budistas, mórmons, wicca, agnósticas ou sem religião. Casadas, separadas, viúvas, solteiras, cisgênero, heterossexuais, uma delas lésbica. Mulheres com demandas de saúde física e mental, com câncer, hipertensão, diabetes, soropositivas, com dificuldade de se locomover, com dores. A grande maioria faz uso de algum tipo de medicação e relataram estar passando ou já terem passado por episódios depressivos. Mulheres que não terminaram o ensino fundamental, outras que estão cursando o ensino superior e muitas que relatam ter tido o sonho de fazer uma faculdade.

São muitos os cruzamentos que fazem parte dos processos de subjetivação dessas mulheres que se encontram em um espaço comum, um local de formação teórica e trabalho comunitário que visa o trabalho com outras tantas mulheres que também transitam por esses milhares de cruzamentos que estabelecem modos de viver e estar no mundo. Isso fez com que a relação dessas mulheres com o Projeto Mulheres da Paz fosse diferente.

Essas diferenças se referem, por exemplo, ao tempo disponível para estarem engajadas nas atividades, aos recursos financeiros, ao desejo de participar de discussões que são divergentes das suas crenças religiosas, à possibilidade de fazer algo para si, a conseguir enfrentar as situações de violência vividas em suas casas, à permissão do companheiro que, muitas vezes, barra a ida dela até a sede do projeto, à apropriação teórica de alguns temas, à capacidade de ler e escrever e, até mesmo, ao modo de andar pelas ruas, frequentar outros espaços (públicos), conhecer mais serviços do que outros, 
no tom de voz, na articulação da fala, e outros tantos efeitos produzidos pelas relações de saber-poder que permeiam suas histórias.

Destaca-se também os marcadores sociais da equipe de referência desse projeto social até o mês de fevereiro de 2016. Cinco mulheres, quatro delas brancas, uma delas negra, três delas com ensino superior completo, uma delas realizando o estágio profissional do curso de psicologia e a outra realizando o estágio de ensino médio.

Todas com menos de 30 anos e sem filhos/as, quatro de classe média, uma de classe popular. Quatro residentes em Canoas, três moram e conhecem bastante os territórios de paz. Uma reside em Porto Alegre. Todas heterossexuais e cisgêneras. Questões que estabelecem muitas vezes um lugar de "comando", “chefia", "poder", que fez com que as participantes do programa, por vezes, procurassem a equipe a fim de encontrar uma "verdade", uma "resposta", um "diagnóstico" e que, muitas vezes, fez com que elas esperassem que a equipe dissesse o que fazer e como fazer. Este lugar esteve sempre tensionado para que as mulheres da paz ocupassem de fato o lugar de lideranças e promotoras de direitos, e que a equipe promovesse um trabalho com as mulheres da paz e não somente para elas.

O conhecimento da equipe técnica, portador de uma visibilidade social por meio da conclusão de uma graduação carrega o peso de "saber tudo", como elas nos diziam: "tu é psicóloga, tu sabe", disparando o automatismo que está habituado com salas de aula, com as possibilidades de fala, leituras e conceitos, fazendo com que o acesso ao lugar de "saber" e de "fala" fosse facilitado. Elementos que exigiram refletir sobre as diferenças, a fim de tentar não reproduzir relações de opressão, mas sim, promover espaços coletivos de partilha, segurança e escuta.

Adiante serão trazidos os novos rumos que o Projeto Mulheres da Paz em Canoas começou a trilhar. Serão descritas as reformulações pelas quais o programa passou, salientando, em seguida, a relação que este projeto social teve como os processos de subjetivação das entrevistadas e os apontamentos críticos que se pode construir a partir desses descaminhos.

\section{O Projeto Mulheres da Paz em desconstrução}

O PRONASCI chega ao fim ainda em 2012, entretanto, alguns convênios se mantiveram por mais alguns anos para o cumprimento dos objetivos e metas pautados nos editais lançados até a data final do PRONASCI. O convênio da última turma de 
mulheres da paz chegou ao fim em julho de 2015. Com isso o Projeto Mulheres da Paz precisava ser repensado por parte da Diretoria de Projeto Sociais da Secretaria Municipal de Segurança Pública com Cidadania (SMSPC) de Canoas.

Em meados de 2015, surgiu a notícia de que o Projeto Mulheres da Paz teria que passar por transformações para garantir sua continuidade. Notícias que ainda não previam prazos e objetivos definidos. Algumas reuniões aconteceram entre as coordenações locais dos Projetos Mulheres da Paz dos dois Territórios de Paz, no sentido de discutir acerca dos objetivos deste projeto social, os fluxos e demandas, as articulações intersetoriais, além de debatermos os desafios vivenciados no cotidiano do trabalho.

A primeira questão foi: o Projeto Mulheres da Paz estaria acabando? As falas dos(as) gestores(as) repetidamente afirmavam que não, que se tratava de uma reformulação que integraria o trabalho das Mulheres da Paz em um serviço de atendimento a outras demandas. Embora as falas respondessem que não acabaria, ao ler a nova proposta do projeto que passaria a se chamar "Casa da Cidadania", a palavra "mulheres" parecia se esconder em meio aos "egressos do sistema prisional", às "vítimas de violência intrafamiliar", ao "PROCON", à "mediação de conflitos" e aos “ameaçados de morte". Nos moldes de um Centro de Referência em Direitos Humanos, o Projeto Mulheres da Paz tentaria se realocar, dividindo espaço com demandas que eram de outro projeto social também vinculado à SMSPC, o Núcleo de Justiça Comunitária que estava encerrando as atividades e fechando sua sede.

Foram muitas reuniões após a aprovação por parte da prefeitura municipal deste novo modelo de trabalho. Embora alguns pontos tivessem sido pré-estabelecidos pela gestão local, deveríamos nos ater aos processos organizativos do novo trabalho, lançando mão de esforços sistemáticos das equipes para "colocar a Casa da Cidadania para funcionar". Outro aspecto que demandou consideração foi justamente a questão de “como se levaria esta informação às mulheres da paz e de que forma seguiríamos o trabalho com as mesmas"?

Neste quesito, a equipe técnica optou por dar a notícia às mulheres antes da Diretoria de Projetos da SMSPC, levando em consideração que aquele precisaria ser um momento exclusivo das mulheres da paz com as profissionais que trabalhavam com elas no dia-a-dia. O comunicado foi feito no início do mês de setembro de 2015, em uma reunião com todas as participantes do quadrante nordeste. Muitas foram as informações 
compartilhadas com elas. Para explicar que o Projeto Mulheres da Paz estaria mudando, precisou-se descrever e apresentar o "novo modelo" de projeto social, intitulado "Casa da Cidadania”, pois seria por meio deste, que as ações das mulheres da paz seriam integradas.

Após o comunicado da equipe, propusemos um espaço de fala, escuta, opiniões e expressão dos afetos gerados pelo relato por parte das mulheres da paz ali presentes. As participantes prontamente se mostraram incomodadas com as novas notícias, ressaltando o fato de não terem sido consultadas para contribuírem na construção deste novo modelo. Muitas relataram se sentirem traídas, revoltadas, tristes. Outras disseram achar interessante a nova proposta de projeto e que concordavam com a reformulação.

Uma das primeiras questões elencadas por uma das mulheres da paz foi: " $E$ agora se me perguntarem o que eu sou, eu respondo o quê?”. Essa pergunta faz pensar nos efeitos identitários e dos sentidos daquele espaço nos modos de ser e existir daquelas mulheres. Essa questão remeteu também a compreensão da relação desse projeto social com os processos de subjetivação das participantes do programa.

Já era sabido que a neutralidade não cabia na perspectiva escolhida para pesquisa, nem se tinha dúvidas de que o campo é movimento e que, por vezes, é preciso entender aquilo que "desanda". Foram semanas tentando encontrar formas de dizer àquelas mulheres da paz que muitas coisas mudariam e que, como parte dessas mudanças, se previa uma carga de sofrimento, dúvidas e decisões que marcariam a história delas, do programa, das profissionais e da comunidade.

"Nós chegamos até aqui, não é possível que isso acabe, agora que está tudo tão bem, que está bem melhor". Em meio a esses acontecimentos, uma reunião das mulheres da paz com o Secretário Municipal de Segurança Pública na época também ocorreu. Essa reunião teve como objetivo o diálogo por parte da SMSPC com as participantes do programa, a fim de explanar dúvidas quanto à mudança para a Casa da Cidadania.

Repetidamente elas diziam: "mais uma vez é um homem no poder, querendo dizer que a violência contra as mulheres não é a causa do maior número de mortes no município". Essa afirmação remeteu à colocação da diretora executiva da ONU Mulheres, Phumzile Mlambo-Ngcuka (2015), em que ela ressalta a violência contra a mulher como "a violação de direitos humanos mais tolerada no mundo", reiterando que é preciso enfrentar esse crime com urgência. Depois dessa reunião, dispusemos de 
semanas para trabalhar e conversar sobre essas mudanças com o grupo de mulheres e na própria equipe. Ao final deste conjunto de ações (por meio de encontros) os relatos das mulheres da paz ressaltaram a necessidade de união, organização e solidariedade, como condições para a continuidade do trabalho.

Destaca-se que o trabalho realizado com e pelas mulheres da paz estava previsto nas Casas da Cidadania, mas que, a partir das reformulações, passaria a existir o cargo de agentes de ação social, que seriam mulheres da paz contratadas (possuindo carteira assinada) para exercer sua função de trabalho comunitário remunerado voltado para o enfrentamento às violências, mobilização comunitária e educação para os direitos. Como o Projeto do Núcleo de Justiça Comunitária encerrou as atividades e também integraria às Casas da Cidadania, as lideranças (homens e mulheres) que estavam vinculadas a ele também participariam da seleção para as vagas de agentes de ação social. Estariam previstas 15 vagas para o bairro Guajuviras, com uma carga horária de 12 horas semanais. Os pré-requisitos não abarcavam limite de idade, nem grau de escolaridade e somente pessoas que concluíram as formações do Ministério da Justiça por meio do Projeto Mulheres da Paz e Núcleo de Justiça Comunitária poderiam participar da seleção.

As mulheres da paz que não fossem selecionadas, considerando que o número de vagas era bem inferior ao número de participantes, poderiam seguir voluntariamente com suas atividades semanais na sede da Casa da Cidadania, que é a mesma sede do Projeto Mulheres da Paz. Contudo, não receberiam mais a bolsa de $\mathrm{R} \$ 100,00$, prevista para o custeio das passagens.

Por fim, os contornos tomados nesta nova guinada nos projetos sociais da SMSPC de Canoas previam mais mudanças. Em março de 2016 ocorreu a troca do Secretário Municipal de Segurança Pública, reconfigurando novamente o cenário, já que aquela nova gestão carregava em seu histórico a criação destes mesmos projetos sociais nos território de paz em 2009 e 2010.

As expectativas face às reformulações que foram efetivadas e questionadas, mas este será outro (novo ou não) capítulo sobre as políticas públicas de segurança em Canoas, que não cabem no momento neste artigo, ainda que incessantemente movimentem os caminhos das nossas práticas de trabalho/pesquisa. É desafiadora a tentativa de nos localizar num tempo/espaço das políticas públicas sociais de gênero, 
por tamanha imprevisibilidade e tensionamentos vividos velozmente no ano de 2016 na esfera municipal, estadual e federal.

Contudo, ao lançar mão dos relatos das histórias de vida das participantes desse projeto social, podemos entender que estas mulheres vivenciaram um processo de ruptura, de guinada em aspectos de suas vidas, que se transformou depois que iniciaram a formação do Projeto Mulheres da Paz e se reconheceram como parte deste programa. Neste sentido, pautar o enfraquecimento das políticas públicas sociais de gênero, ou até mesmo seu fim, é convocar a discussão sobre os rumos e resultados que posicionamentos como esse podem (re)produzir no cotidiano das relações sociais, especialmente ao que se refere à desigualdade de gênero.

Algumas das mulheres da paz salientam mudanças nas suas relações sociais, familiares e comunitárias. Transformações que implicam nos modos como elas mesmas se percebem hoje e lidam com algumas questões que anteriormente se mostravam mais difíceis de enfrentar.

Elementos como "conseguir falar" e "aprender que se é capaz" estão relacionados com o "se fazer ouvir" e o "aprendizado sobre si mesma". Aspectos que correspondem às relações sociais construídas no decorrer de suas vidas, que foram concebendo maneiras de calar e desencorajar algumas das participantes, mas que ao longo da inserção no programa foram sendo colocadas em questão.

A relação comunitária foi outro fator que apareceu como contribuição do Projeto Mulheres da Paz na vida de algumas entrevistadas. Elas comentaram que passaram a se perceber mais partícipes de suas comunidades. A atenção para a criação de laços de solidariedade e alianças de cidadania foi relatada como um avanço no que diz respeito à ruptura do isolamento social (Barros, 2002). O que antes "era problema dela" começou a ser também "problema meu" como coloca uma das participantes. Além disso, o fato de algumas mulheres da paz passarem a ser reconhecidas como "pessoas de referência" permitiram às suas comunidades outros caminhos de acesso à informação, à escuta e à cidadania. Os relatos das mulheres da paz remetem à construção de uma rede social que permitiu o contato com a multiplicidade que opera na ordem do coletivo como nos situa Regina Benevides de Barros (2002). Recusar o individualismo naturalizado no nosso cotidiano, participando de espaços geradores de "outros encontros" com essa comunidade (seja a vizinhança, os serviços públicos ou ainda as redes sociais virtuais) é contribuir na circulação das invenções microssociais de novas formas de vida. 
Os conteúdos abordados no programa que alçou essas participantes ao lugar de mulheres da paz potencializaram outros encontros. Para uma das entrevistadas "as pessoas lhe procuram", a UBS sabe quem é ela, não por ela ser usuária do serviço, mas por agora ela ser a extensão de um trabalho comunitário em rede, em que ela passa a também "poder ajudar e orientar". A autora mexicana Gloria Anzaldúa (2005) salienta que romper com essa visão dicotômica a respeito do indivíduo, da relação sujeitoobjeto, que ainda opera na nossa sociedade é o início de uma longa luta que poderá se tornar a direção para o fim das violências, sobretudo se nosso caráter mestiço epistemológico nos ajudar a descolonizar nossas formas de pensar.

\section{Considerações finais}

O espaço do Projeto Mulheres da Paz foi uma estratégia construída com o objetivo de lutar pelo fim das violências contra as mulheres. Uma das participantes, sobrevivente da violência doméstica, salientou que "por estar viva, deve essa luta para a sociedade" e que é grata ao projeto social por possibilitar esse espaço de trabalho e formação a ela, afirmando ainda que "muitas mulheres precisam das mulheres da paz".

Entretanto, como apresentado, o terreno das políticas sociais de gênero enfrenta um solo movediço. Chão que é desestabilizado pela interseccionalidade de marcadores sociais que o planejamento de um projeto social para mulheres deve abarcar, além do permanente esforço pela busca de visibilidade política para ações que encorajam a luta pela igualdade/equidade de gênero em uma perspectiva interseccional.

Contudo, se "muitas mulheres precisam das mulheres da paz", e embora, as mulheres possam seguir atuando voluntariamente nas suas comunidades, o indicativo é que com o fim de iniciativas como essa, demandas como o enfrentamento às violências de gênero siga ainda mais descoberta, silenciada e naturalizada. Ao que parece, barricadas foram colocadas nesta história que avivava outras possibilidades de ser para essas mulheres.

Apesar disso, as participantes do programa ainda dizem "uma vez mulher da paz, sempre mulher da paz", sugerindo que será preciso reinventar brechas. Embora o cenário que se apresenta neste percurso não seja otimista, a história dessas mulheres da paz de Canoas pode servir como ferramenta potente para reconstruções necessárias no âmbito das políticas públicas de gênero. 


\section{Referências}

Anzaldúa, G. (2005). La conciencia de la mestiza: rumo a uma nova consciência. Revista Estudos Feministas, 13(3), 704-719. https://dx.doi.org/10.1590/S0104026X2005000300015

Benevides de Barros, R. (1997). Dispositivos em ação: o grupo.Em A Silva \& cols. (Orgs.), Cadernos de Subjetividade (pp. 183-191). São Paulo: Hucitec.

Butler, J. (2003). Problemas de Gênero: feminismo e subversão da identidade. Rio de Janeiro: Civilização Brasileira.

Costa, A. A. A. (2005). O Movimento Feminista No Brasil: Dinâmicas De Uma Intervenção Política. Revista Gênero, v. 5, n. 2, p.9-35.

Crenshaw, K. (2002). Documento para o encontro de especialistas em aspectos da discriminação racial relativos ao gênero. Revista Estudos Feministas, 10(1), 171188. https://dx.doi.org/10.1590/S0104-026X2002000100011

Foucault, M. (1994). História da Sexualidade II: O uso dos prazeres. 7ed, Rio de Janeiro: Edições Graal.

Lei ordinária $\mathrm{N}^{\mathrm{o}}$ 11530, de 24 de outubro de 2007. (2007, 24 de outubro). Institui o Programa Nacional de Segurança Publica Com Cidadania - Pronasci e da Outras Providencias. Brasília, DF: Presidência da República. Disponível em:< http://portal.mj.gov.br/pronasci/main >

Mayorga, C. (2014). Algumas contribuições do feminismo à psicologia social comunitária. Athenea Digital, 221-236. http://dx.doi.org/10.5565/rev/athenead/v14n1.1089

Ministério da Justiça. (2009). Mulheres da Paz: Formação para cultivar a paz nas comunidades. PRONASCI. Brasília.

Ministério da Justiça. Secretaria Nacional de Segurança. (2012). Manual de orientações aos proponentes para elaboração de propostas Via SICONV nas ações Mulheres da Paz e Protejo edital/2012, Anexo IV. Brasília.

Nardi, H. C. (2006). Ética, trabalho e subjetividade: trajetória de vida no contexto das transformações do capitalismo contemporâneo. Porto Alegre: UFRGS.

Pinheiro, A. C. O. (2013). Gênero e segurança pública: uma análise da ação de segurança pública "Projeto Mulheres da Paz". Dissertação de mestrado em Sociologia Política. Universidade Estadual Do Norte Fluminense Darcy Ribeiro. Campo dos Goyatacazes, Rio de Janeiro.

Secretaria Especial de Políticas para as Mulheres. (2008). Plano Nacional de Enfrentamento da Violência contra as mulheres. Brasília.

Teixeira, A. B. (2009). As políticas de segurança e a violência contra as mulheres: a luta por visibilidade, direitos e reconhecimento da diversidade. In: Cadernos Temáticos da Conferência de Segurança. Movimentos Sociais e Segurança Pública: a construção de um campo de direitos. Ano1. № 9. Ministério da Justiça, Brasília. 